\title{
Group Contests with Complementarities in Efforts
}

\author{
Martin Kolmar \\ Hendrik Rommeswinkel
}

CESIFO WORKING PAPER No. 3136

CAtegory 2: Public Choice

JULY 2010

An electronic version of the paper may be downloaded
- from the SSRN website:
- from the RePEc website:
from the CESifo website: 


\title{
Group Contests with Complementarities in Efforts
}

\begin{abstract}
Usually, groups increase their productivity by the specialization of their group members. In these cases, group output is no longer simply a sum of individual outputs. We analyze contests with group-specific public goods that allow for different degrees of complementarity between group members' efforts. More specifically, we use a Tullock contest success function and a CES-impact function. We show that in equilibrium the degree of complementarity is irrelevant if groups do not differ in size and group members have an identical valuation of the public good. The equilibrium is discontinuous as the CES function converges to the CobbDouglas case. Except for the effects at the discontinuity, higher complementarity tends to favor larger groups. In groups with diverse valuations, higher complementarity also leads to higher similarity in group members' efforts, which however is not necessarily an advantage for a more diverse group.
\end{abstract}

JEL-Code: D74, H41.

Keywords: contests, public goods.

Martin Kolmar

Institute for Public Finance and

Financial Law

University of St. Gallen

Varnbüelstrasse 19

$\mathrm{CH}-9000$ St. Gallen

Switzerland

martin.kolmar@unisg.ch
Hendrik Rommeswinkel

Institute for Public Finance and Financial Law

University of St. Gallen

Varnbüelstrasse 19

CH - 9000 St. Gallen

Switzerland

hendrik.rommeswinkel@unisg.ch

July 19, 2010 


\section{Introduction}

With only a few exceptions, the literature on group contests ${ }^{1}$ has focused attention on impact functions ${ }^{2}$ that are additively separable in the effort levels of its members. Additive separability of individual efforts is an important starting point for the analysis of group contests. However, it is clear that efforts of different group members are incomplete substitutes in a number of examples. In R\&D races, where teams of researchers develop new technologies, the whole project is often divided into different, more or less complementary sub-projects that are carried out by different researchers. In military conflicts the armed forces are highly specialized and often divided into complementary units. The same is true for the standard lobbying case if representatives of different firms or organizations lobbying for the same policy differ in qualifications and specialize accordingly. In sports contests, team members are usually specialized with respect to qualifications that complement each other in a non-additive way. This list of examples could be arbitrarily extended because the mere idea of specialization implies that there is a certain degree of complementarity in team or group production. Individuals differ in talents, qualifications, and affections such that we can expect that individuals in a group or team will specialize to increase overall productivity. We can expect a certain degree of complementarity between the efforts of the group members. Alchian and Demsetz (1972) see the non-additivity as constitutive for group or team production (pp. 777): "Resource owners increase productivity through cooperative specialization. [...] With team production it is difficult, solely by observing total output, to either define or determine each individual's contribution to this output of the cooperating inputs. The output is yielded by a team, by definition, and it is not a sum of separable outputs of each of its members. [...] Usual explanations of the gains from cooperative behavior rely on exchange and production in accord with the comparative advantage specialization principle with separable additive production. However [...] there is a source of gain from cooperative activity involving working as a team, wherein individual cooperating inputs do not yield identifiable, separate products which can be summed to measure the total output."

\footnotetext{
${ }^{1}$ The literature on contests between groups has recently been surveyed by Corchón, 2007, Section 4.2, Garfinkel \& Skaperdas, 2007, Section 7, and Konrad, 2009, Chapters 5.5 and 7.

${ }^{2}$ The term is defined and discussed in Münster (2009).
} 
If non-additive effort is the rule rather than the exception, it is important to understand how the degree of substitution between individual efforts influences behavior in and the outcome of the contest. In this paper we analyze a situation where efforts of group members can be imperfect substitutes. In order to capture this idea, we assume that individual efforts $x_{i}^{k}$ are mapped onto group output (which itself is the input in the contest success function) by means of a CES-impact function, $\left(\sum\left(x_{i}^{k}\right)^{\gamma}\right)^{1 / \gamma}$, with variable elasticity of substitution $1 /(1-\gamma)$, ranging from perfect complements $(\gamma \rightarrow-\infty)$ to perfect substitutes $(\gamma \rightarrow 1)$. The contest is of the Tullock type, and the rent is a group-specific public good (i.e. nonrival in consumption). ${ }^{3}$

If groups instead of individuals compete in a contest, the well-known free-rider problem among group members exists. Every individual bears the full costs of its investments, whereas the benefits partly spill over to the rest of the group (Katz, Nitzan, \& Rosenberg, 1990; Esteban \& Ray, 2001; Epstein \& Mealem, 2009; Nitzan \& Ueda, 2009). Depending on the sharing rule applied, this problem may also exist for a private good (Nitzan, 1991a, 1991b; Esteban \& Ray, 2001; Nitzan \& Ueda, 2009). In the recent literature, Baik (2008), Epstein and Mealem (2009), and Lee (2008) have presented contest models with group-specific public goods. A major result in Baik (2008) is that in a model with linear effort costs and additively linear impact functions only those group members with the highest valuation of the rent make positive investments in the contest. In his model, efforts of group members are perfect substitutes and therefore the optimality conditions given by the first-order conditions cannot hold for different valuations. With several group members having the maximal valuation among the group, there exist multiple equilibria, since the first order condition only defines the total effort spent by the group. Epstein and Mealem (2009) stick to the assumption of additive separability of individual effort in the group-production functions but introduce decreasing returns to investment. Using a technology that fulfills standard Inada conditions they show that every individual makes positive investments. Their model is isomorphic to a model with linear impact functions and in which individuals face strictly convex costs. In this sense, effort levels are no longer perfect substitutes, but the impact function is still additively separable. Lee (2008) focuses attention on weakest-link impact functions. The perfect complementarity of efforts creates a coordination problem between group members which gives rise to multiple equilibria, and the equilibrium with highest

\footnotetext{
${ }^{3}$ Münster (2009) provides an axiomatic foundation for the Tullock function for group contests.
} 
efforts is determined by the valuation of the player with minimum valuation within each group. Hence, the models of Baik (2008) and Lee (2008) represent the "polar" cases with respect to the elasticity of substitution between group members. ${ }^{4}$

Our model generalizes these results. It turns out that the equilibrium of our model is unique for all values of $\gamma \in\{(-\infty, 0),(0,1)\}$ ( $\gamma=0$ can only be covered by a limit result). If there is no within-group heterogeneity with respect to valuations of the prize and all groups have the same size, the equilibrium is independent of the elasticity of substitution. This result is a useful starting point because it shows that the elasticity of substitution per se has no impact on behavior in the contest: contrary to the cursory idea that increasing the degree of complementarity between group-members' efforts helps to internalize the existing free-rider problem. ${ }^{5}$ At the same time, this result shows that the standard results on group contests are robust with respect to variations in the elasticity of substitution under these assumptions.

An immediate implication of this irrelevance result is the conjecture that the elasticity of substitution becomes relevant if there is heterogeneity between group members with respect to the valuations of the rent and/or heterogeneity between groups with respect to group size, if at all.

A first important result of this general case is the characterization of active and inactive groups. We know from Hillman and Riley (1987) and Stein (2002) (for contests between individuals) that players may prefer not to participate in a contest if valuations are sufficiently heterogenous. This result carries over to the case of group contests. However, if a group is active, every member of this group exerts positive effort. In addition, the equilibrium strategies are continuous (but not necessarily continuously differentiable) in the elasticity of substitution everywhere except at $\gamma=0$, because groups that become inactive or active do this in a "smooth" way.

The limit behavior of our model is of particular interest. First, the results for the two limiting cases $\gamma \rightarrow 1$ and $\gamma \rightarrow-\infty$ have been analyzed by Baik (1993, 2008) and Lee (2008). In the former case, equilibrium effort is determined by the players with

\footnotetext{
${ }^{4}$ One might argue that the best-shot technology where only the maximum effort counts is even more extreme, but it is relatively obvious that as for the case of perfect substitutes the equilibrium with maximum effort is also determined by the players with maximum valuations.

${ }^{5}$ Hirshleifer (1983) argues for the special case of perfect complements ("weakest-link" technology) that the complementarity between group members' efforts helps solving the free-rider problem.
} 
the maximum valuations, and in the latter case by the players with the minimum valuation in each group, which implies that group size does not matter. However, there are multiple equilibria in both cases. We can show that our model is consistent with both results in the sense that the equilibrium converges to one of the equilibria of the boundary cases. As a consequence, the uniqueness of the equilibrium for all values of $\gamma$ except 1 and $-\infty$ shows that the multiplicity problems are not robust with respect to small changes in the elasticity of substitution.

For all other values of $\gamma$, relative group size is important for the resulting equilibrium. This observation allows it to build a bridge to the discussion about the so-called "group-size paradox" (Olson, 1965; Esteban \& Ray, 2001; Nitzan \& Ueda, 2009) that "larger groups may be less successful than smaller groups in furthering their interests" (Esteban \& Ray, 2001, p.663). We can show that the possible reversal of the group-size paradox occurs also in our model if $\gamma \in(0,1)$. In the limiting case $\gamma=1$, group size is irrelevant, and a reduction in the elasticity of substitution helps the relatively large groups at the expense of the relatively small ones. In the limit case $\gamma \rightarrow 0^{+}$only the largest groups stay active, and if there is a single largest group, it wins almost for sure, irrespective of its relative valuation of the rent. This finding shows that the reversal of the group-size paradox is not restricted to sufficiently convex cost functions (Esteban \& Ray, 2001). A decrease in the elasticity of substitution has the same effect.

The fact that we have covered all possible elasticities of substitution allows it to incorporate the discussion about the relative advantage of large or small groups into a larger picture. For higher degrees of complementarity $(\gamma<0)$, we can show that the advantage of larger groups is reversed as soon as $\gamma$ turns negative. As $\gamma$ approaches 0 from below, large groups become inactive, and in the limiting case we end up with an arbitrarily large advantage of the smallest group. This discontinuity of the model at $\gamma=0$ is a consequence of the CES-impact function that increasingly leverages differences in group size as $\gamma$ approaches 0 . However, smaller values of $\gamma$ tend to help larger groups also if $\gamma<0$. Hence, if deviations from the perfect-substitutes case are the rule rather than the exception for most empirical applications, there is no immediate answer to the question of whether large or small groups have an advantage in the contest. It depends on the strength of the complementarities. Coming back to the discussion about free-riding and the degree of complementarity, the results on relative group size show that in fact more complementary impact functions ceteris 
paribus help larger groups at the expense of smaller ones, and in this sense it helps alleviating the free-rider problem that is more severe the larger the relative size of the group.

The paper is organized as follows. We introduce the model in Section 2 and start with introductory examples in Section 3. We characterize the simultaneous Nash equilibrium of the general model in Section 4. In subsection 4.1 we will state convergence results for $\gamma$ approaching 1,0 , and $-\infty$, and in subsection 4.2 the comparative-static results are summarized. Section 5 concludes.

\section{The model}

Assume that $n$ groups compete for a given rent $R . m_{i}$ is the number of individuals in group $i$ and $k$ is the index of a generic member of this group. The rent is a group-specific public good that has a value $v_{i}^{k}>0$ to individual $k$ of group $i$, and we assume the following ordering: $v_{i}^{\max } \geq \ldots \geq v_{i}^{\min } \cdot p_{i}$ represents the probability of group $i=1, \ldots, n$ to win the contest. It is a function of some vector of aggregate group output $q_{1}, \ldots, q_{n}$. We focus on Tullock-form contest success functions where the winning probability of a group $i$ is defined as:

Assumption 1: $p_{i}\left(q_{1}, \ldots, q_{n}\right)=\frac{q_{i}}{\sum_{j=1}^{n} q_{j}}, i=1, \ldots n$.

The aggregate group output depends on individual effort $x_{i}^{k}, Q_{i}=q_{i}\left(x_{i}^{1}, \ldots, x_{i}^{m_{i}}\right)$, $i=1, \ldots, n$. Following the literature we will call $q_{i}($.$) impact functions in the following$ and make the assumption that they are of the constant elasticity of substitution (CES) type.

Assumption 2: $q_{i}\left(x_{i}^{1}, \ldots, x_{i}^{m_{i}}\right)=\left(\sum_{l=1}^{m_{i}}\left(x_{i}^{l}\right)^{\gamma}\right)^{1 / \gamma}, \gamma \in(-\infty, 1], i=$ $1, \ldots n$.

Note that we obtain a closed-form solution only if $\gamma \neq 0$. The Cobb-Douglas case $\gamma \rightarrow 0$ will be covered by a limit result.

Assumption 3: Individuals are risk neutral, face linear costs, and maximize their net rent. 
It follows from Assumptions 1, 2, and 3 that the individual utility functions are as follows:

$$
\pi_{i}^{k}\left(x_{1}^{1}, \ldots, x_{n}^{m_{n}}\right):=\pi_{i}^{k}\left(x_{i}^{k}, x_{/ x_{i}^{k}}\right)=v_{i}^{k} \frac{\left(\sum_{l}\left(x_{i}^{l}\right)^{\gamma}\right)^{1 / \gamma}}{\sum_{j}\left(\sum_{l}\left(x_{j}^{l}\right)^{\gamma}\right)^{1 / \gamma}}-x_{i}^{k},
$$

where $x_{/ x_{i}^{k}}$ refers to the vector $x_{1}^{1}, \ldots, x_{n}^{m_{n}}$ without $x_{i}^{k}$. We are looking for a Nash equilibrium of this game where individuals choose their effort $x_{i}^{k}$ simultaneously to maximize their expected utility,

$$
x_{i}^{k *} \in \arg \max _{x_{i}^{k}} \pi_{i}^{k}\left(x_{i}^{k}, x_{-x_{i}^{k}}^{*}\right) \quad \forall i, k .
$$

where "*" refers to equilibrium values.

\section{$3 \quad$ Introductory examples}

The explanatory variable that is new compared to the existing literature is the elasticity of substitution. In this section we analyze three simple examples that provide intuition for the relevance of this variable in contests. We will come back to these examples throughout the main part of the paper to provide intuition for the general results. As we will see, the elasticity is only relevant if the valuations between members of the same group differ or if groups differ in size. All three examples restrict attention to a contest between two groups, 1 and 2, with $m_{1}$ and $m_{2}$ members. The valuation of the group members are either $v_{i}^{\max }$ or $v_{i}^{\min }, v_{i}^{\max } \geq v_{i}^{\min }, i=1,2$. The examples are chosen to highlight the central mechanisms of this model, we therefore delegate all technical details about the existence of interior solutions, active and inactive groups and group members, etc. to the next section.

The first-order condition that characterizes an interior solution to the individual optimization problems of a member $k$ of group $i$ is given by

$$
\frac{\partial \pi_{i}^{k}\left(x_{1}, \ldots, x_{n}, \gamma\right)}{\partial x_{i}^{k}}=v_{i}^{k} \frac{q\left(x_{j}, \gamma\right)}{\left(\sum_{i=1}^{2} q\left(x_{i}, \gamma\right)\right)^{2}} \frac{\partial q\left(x_{i}, \gamma\right)}{\partial x_{i}^{k}}-1=0 ; k=L, H ; i=1,2,
$$

which is a simple "marginal revenues equal marginal costs" condition.

Example 1: In this example we restrict attention to groups of equal size $m_{1}=$ $m_{2}=m$ with only a single valuation of the members of a given group, $v_{i}^{\text {min }}=$ $v_{i}^{\max }=v_{i}, i=1,2$. We assume that all members of a given group behave identically. 
Using this fact, it follows that $\frac{\partial q\left(x_{i}, \gamma\right)}{\partial x_{i}^{k}}=q\left(x_{i}, \gamma\right) /\left(m_{i} x_{i}\right)$, and (3) can be simplified to yield

$$
v_{i} \frac{q\left(x_{j}, \gamma\right)}{\left(q\left(x_{i}, \gamma\right)+q\left(x_{j}, \gamma\right)\right)^{2}} \frac{q\left(x_{i}, \gamma\right)}{m x_{i}}-1=0, \quad i=1,2, j \neq i
$$

It follows that $x_{1} v_{2}=v_{1} x_{2}$ in an interior equilibrium, and finally

$$
x_{1}\left(v_{1}, v_{2}\right)=\frac{v_{1}^{2} v_{2}}{m\left(v_{1}+v_{2}\right)^{2}}, \quad x_{2}\left(v_{1}, v_{2}\right)=\frac{v_{1} v_{2}^{2}}{m\left(v_{1}+v_{2}\right)^{2}},
$$

investments in the contest are independent of $\gamma$. This example shows that the elasticity of substitution does not play a role if there is no within-group heterogeneity and groups are of equal size. The reason for this result is the combination of a constant-return to scale impact function with a contest success function that is homogenous of degree zero. Conversely, it must be either within-group heterogeneity and/or differences in group size that may cause behavioral changes due to changes in $\gamma$. The next two examples show that this may in fact be the case.

Example 2: Second, we assume that $v_{1}=v_{2}$ but allow for differences in group size. In this case, (3) implies

$$
x_{1}\left(m_{1}, m_{2}, \gamma, v\right)=\frac{v m_{1}^{\frac{1-2 \gamma}{\gamma}} m_{2}^{\frac{1-\gamma}{\gamma}}}{\left(m_{1}^{\frac{1-\gamma}{\gamma}}+m_{2}^{\frac{1-\gamma}{\gamma}}\right)^{2}}, x_{2}\left(m_{1}, m_{2}, \gamma, v\right)=\frac{v m_{1}^{\frac{1-\gamma}{\gamma}} m_{2}^{\frac{1-2 \gamma}{\gamma}}}{\left(m_{1}^{\frac{1-\gamma}{\gamma}}+m_{2}^{\frac{1-\gamma}{\gamma}}\right)^{2}},
$$

if all members of the same group behave identically. In this case, individual efforts depend on the size of the groups. As we will discuss in greater detail in Section 4.2, this finding allows to perceive the discussion about the group-size paradox in a more general and comprehensive way.

Example 3: In the last example we assume that $m_{1}=m_{2}$ but $v_{1}^{\min }=v_{2}^{\min }=$ $v^{\min } \leq v^{\max }=v_{1}^{\max }=v_{2}^{\max }$. The population is divided into $m^{\min }=m^{\max }=m / 2$ for both groups. Again, (3) can be used to get the following symmetric equilibrium:

$$
\begin{aligned}
& x^{\max }\left(v^{\min }, v^{\max }, m, \gamma\right)=\frac{v^{\max }}{2 m\left(\left(\frac{v^{\min }}{v^{\max }}\right)^{\frac{\gamma}{1-\gamma}}+1\right)}, \\
& x^{\min }\left(v^{\min }, v^{\text {min }}, m, \gamma\right)=\frac{v^{\min }}{2 m\left(\left(\frac{v^{\max }}{v^{\min }}\right)^{\frac{\gamma}{1-\gamma}}+1\right)} .
\end{aligned}
$$

As in the second example, $\gamma$ may influence the outcome of the game if differences among the valuations of the rent among the group members exist. 


\section{The general case}

We now turn to the analysis of the general case. In order to have a lean notation, let $y_{i}^{k}=\left(x_{i}^{k}\right)^{\gamma}$ and $Y_{i}=\left(\sum_{l} y_{i}^{l}\right)$. Further, $Q=\sum_{j} Q_{j}=\sum_{j} Y_{j}^{\frac{1}{\gamma}}=Y_{i}^{\frac{1}{\gamma}}+\sum_{j \neq i} Y_{j}^{\frac{1}{\gamma}}=$ $Q_{i}+Q_{/ i}$ in the following. While deriving the equilibrium strategies, we will omit the parameters of these functions for better readability (e.g $y_{i}^{k}$ instead of $y_{i}^{k}\left(\gamma, x_{i}^{k}\right)$ ). Hillman and Riley (1987) and Stein (2002) have shown that groups/individuals may prefer to stay inactive if the size of all groups is equal to 1. Baik (2008) has shown that only group members with maximum valuation participate in a contest. Hence, it is possible that some individuals and/or groups will stay inactive in our setup. We therefore start with an analysis of active individuals and groups.

Definition 1: An individual $k$ of group $i$ is said to participate if $x_{i}^{k}>0$. A group $i$ is said to participate if there exists some $k$ such that $x_{i}^{k}>0$. A group is said to fully participate if $\forall k: x_{i}^{k}>0$.

Lemma 1: In a Nash equilibrium of a contest fulfilling Assumptions 1, 2, and 3 if a group participates, it fully participates.

The proof of this as well as the next Lemma can be found in the appendix. Lemma 1 implies that in order to determine whether an individual participates, it is sufficient to determine whether its group participates. Let $V_{i}(\gamma) \equiv\left(\sum_{l} v_{i}^{l \frac{\gamma}{1-\gamma}}\right)^{\frac{1-\gamma}{\gamma}}$. Without loss of generality, suppose the groups are ordered such that $V_{i}(\gamma) \geq V_{i+1}(\gamma)$ for a given $\gamma \cdot Q_{i}^{*}(\gamma)$ and $Q^{*}(\gamma)$ shall denote $Q_{i}$ and $Q$ in equilibrium. The following Lemma determines the groups that participate in equilibrium.

Lemma 2: a) There exist best response strategies of the members of a group, if and only if the following group best response function is fulfilled:

$$
\hat{Q}_{i}\left(\gamma, Q_{/ i}\right)=\max \left(0, \sqrt{Q_{/ i} V_{i}(\gamma)}-Q_{/ i}\right)
$$

b) Groups $1 \ldots n^{*}(\gamma)$ participate, where $n^{*}(\gamma) \equiv \arg \max _{i} i$ such that $V_{i}(\gamma)>Q^{*}(\gamma)$.

c) If the Nash equilibrium is unique, $Q_{i}^{*}(\gamma)$ and $Q^{*}(\gamma)$ are continuous functions for $\gamma \neq 0$.

Lemma 2.c is useful for the comparative-static analysis. Given that the number and identity of active groups depends on $\gamma$, it is a priori not clear that aggregate effort and indirect utilities are continuous in $\gamma$. The Lemma reveals that continuity is in fact guaranteed except at $\gamma=0$. The economic intuition is as follows: Assume 
that $\hat{\gamma}$ is a point where a formerly active group becomes inactive or a formerly inactive group becomes active. The aggregate group effort of the active group is continuously reduced to zero as $\gamma$ approaches $\hat{\gamma}$, and the formerly inactive group continuously increases its effort from 0 as $\gamma$ increases from $\hat{\gamma}$. Hence, there is a "smooth" fade out or fade in of groups at those points.

The following proposition characterizes the unique Nash equilibrium of the game. For readability, the strategies $x_{i}^{k}$ are defined as functions of $Q^{*}(\gamma)$ and $V_{i}(\gamma)$.

Proposition 1. The unique Nash equilibrium of the game characterized by Assumptions 1,2, and 3 is given by strategies $x_{i}^{k^{*}}(\gamma)$ that fulfill

$$
x_{i}^{k^{*}}(\gamma)=\left\{\begin{array}{ll}
Q^{*}(\gamma)\left(1-\frac{Q^{*}(\gamma)}{V_{i}(\gamma)}\right) \frac{\left(v_{i}^{k}\right)^{\frac{1}{1-\gamma}}}{V_{i}(\gamma)^{\frac{1}{1-\gamma}}}, & V_{i}(\gamma)>Q^{*}(\gamma) \\
0, & V_{i}(\gamma) \leq 0
\end{array},\right.
$$

where $Q^{*}(\gamma)=\frac{n^{*}(\gamma)-1}{\sum_{i=1}^{n^{*}(\gamma)} V_{i}(\gamma)^{-1}}$ and $n^{*}(\gamma)$ is defined in Lemma 2.a and groups are ordered such that $V_{i}(\gamma) \geq V_{i+1}(\gamma)$.

Proof. To obtain $Q^{*}(\gamma)$ we sum (7) over all $i \leq n^{*}(\gamma)$ :

$$
Q^{*}(\gamma)=\frac{n^{*}(\gamma)-1}{\sum_{i=1}^{n^{*}(\gamma)} V_{i}(\gamma)^{-1}}
$$

With an explicit solution for $Q^{*}(\gamma)$, we can now determine individual expenditures $x_{i}^{k^{*}}(\gamma)$ by solving equation (7) using (9). The participation condition of a group is given by Lemma 2, while Lemma 1 ensures that there does not exist an incentive for any group member to deviate to $x_{i}^{k}=0$. It was further shown that the first-order conditions return local maxima. Since the system of equations given by the firstorder conditions of the participating groups has a unique solution this is indeed the unique Nash equilibrium.

A focal special case has equal group size $m_{i}=m \forall i$ and no intra-group heterogeneity $v_{i}^{k}=v_{i} \forall k \forall i$. The following corollary of Proposition 1 can then be established. Corollary 1: If $m_{i}=m \forall i$ and $v_{i}^{k}=v_{i} \forall k \forall i$ the equilibrium efforts are independent of $\gamma$.

Proof. Inserting $m_{i}=m \forall i$ and $v_{i}^{k}=v_{i} \forall k \forall i$ in (9) it can be shown that $v_{i} x_{i}=$ $\left(v_{i}-m \sum x_{j}\right)\left(\sum x_{j}\right) \forall i$, which is independent of $\gamma$. 
The corollary shows that the elasticity of substitution is only relevant if there is either heterogeneity with respect to valuations within groups and/or heterogeneity with respect to group size. In all other cases equilibrium behavior does not depend on $\gamma$. This finding implies that an increase in complementarity between group members' effort per se has no effect on the within-group free-rider problem, as could have been conjectured from Hirshleifer (1983). A further implication of the result is that the results on group contests that have been derived in the literature for the case of perfect substitutes or perfect complements carry over to arbitrary elasticities of substitution if groups differ only in their valuations of the rent.

\subsection{Convergence Results}

Before we move on to the core convergence results with respect to $\gamma$ and the comparative statics of the model, let us first note that the winning probability of group $i$ takes the form:

$$
\frac{Q_{i}{ }^{*}(\gamma)}{Q^{*}(\gamma)}=\left(1-\frac{Q^{*}(\gamma)}{V_{i}}\right)
$$

which can be derived from (7). We will now state convergence results where $\gamma$ approaches 1,0 , and $-\infty$.

Proposition 2. For $\gamma \rightarrow 1$, we get $\frac{x_{i}^{k^{*}}}{X_{i}^{*}}=0$ if $\exists v_{i}^{l}>v_{i}^{k}$ and $\frac{1}{\sharp\left\{v_{i}^{l}: v_{i}^{l}=v_{i}^{k}\right\}}$ otherwise.

Proof. It is straightforward to derive the following equation from (8):

$$
\frac{x_{i}^{k^{*}}(\gamma)}{X_{i}^{*}(\gamma)}=\frac{\left(v_{i}^{k}\right)^{\frac{1}{1-\gamma}}}{\sum_{l}\left(v_{i}^{l}\right)^{\frac{1}{1-\gamma}}}
$$

For the limit it then holds:

$$
\lim _{\gamma \rightarrow 1} \frac{\left(v_{i}^{k}\right)^{\frac{1}{1-\gamma}}}{\sum_{l}\left(v_{i}^{l}\right)^{\frac{1}{1-\gamma}}}=\lim _{\gamma \rightarrow 1}\left(\sum_{l}\left(\frac{v_{i}^{l}}{v_{i}^{k}}\right)^{\frac{1}{1-\gamma}}\right)^{-1}= \begin{cases}0, & \exists v_{i}^{l}>v_{i}^{k} \\ \frac{1}{\sharp\left\{v_{i}^{l}: v_{i}^{l}=v_{i}^{k}\right\}}, & \text { else }\end{cases}
$$

Proposition 2 shows that for $\gamma$ increasing towards one, the group members with lower valuations will decrease their efforts towards zero, and only the group members with the highest valuations contribute. If there is more than one individual with the 
highest valuation, we converge to an equilibrium where those individuals contribute equally. ${ }^{6}$

Next we will analyze the other boundary case when $\gamma$ approaches $-\infty$. In order to have a lean notation we denote $\lim _{\gamma \rightarrow-\infty} f(\gamma)$ by $f(-\infty)$ for all functions $f($.$) :$

Proposition 3. For $\gamma \rightarrow-\infty$, we obtain:

a) $\lim _{\gamma \rightarrow-\infty} x_{i}^{k^{*}}= \begin{cases}0, & V_{i}(-\infty) \leq Q^{*}(-\infty) \\ \frac{1}{m_{i}} \frac{n^{*}(-\infty)-1}{\sum_{j} \sum_{l} 1 / v_{j}^{l}}\left(1-\frac{\left(n^{*}(-\infty)-1\right) \sum_{l} 1 / v_{i}^{l}}{\sum_{j} \sum_{l} 1 / v_{j}^{l}}\right), & V_{i}(-\infty)>Q^{*}(-\infty)\end{cases}$

b) $\lim _{\gamma \rightarrow-\infty} \frac{x_{i}^{k^{*}}(\gamma)}{X_{i}^{*}(\gamma)}=\frac{1}{m_{i}}$

c) $\lim _{\gamma \rightarrow-\infty} Q^{*}=\frac{n^{*}(-\infty)}{\sum_{j} \sum_{l} 1 / v_{j}^{l}}$

d) $\lim _{\gamma \rightarrow-\infty} \frac{Q_{1}^{*}}{Q^{*}}=1-\frac{\left(1-n^{*}(-\infty)\right) \sum_{l} 1 / v_{i}^{l}}{\sum_{j} \sum_{l} 1 / v_{j}^{l}}$

where $n^{*}(-\infty)$ is the maximal $\zeta$ such that $\zeta-1 \leq \frac{\sum_{j=1}^{p} \sum_{l} 1 / v_{j}^{l}}{\sum_{l} 1 / v_{i}^{l}}$.

The results follow directly from the determination of the limit of (8).

Proposition $3 \mathrm{~b}$ ) shows that (as expected given the results by Lee (2008)) all group members participate with equal amounts. In this sense, for $\gamma$ near $-\infty$, we obtain similar results as for a $\min (. .$.$) impact function. However, this function$ creates multiple equilibria with an associated equilibrium-selection problem. Given the uniqueness of equilibria for all finite $\gamma$, our limit result can be interpreted as an equilibrium-selection mechanism where individual contributions depend on the harmonic mean of the valuations.

Next we look at the limit behavior for $\gamma \rightarrow 0$. It turns out that we have to consider $\gamma \rightarrow 0^{+}$and $\gamma \rightarrow 0^{-}$separately because the problem may not be continuous at this point.

Proposition 4. Suppose $\forall i: m_{i} \geq m_{i+1}$. For $\gamma \rightarrow 0^{+}$, we obtain:

a) If $n^{*}$ is either defined by $m_{1}=\cdots=m_{n^{*}}>m_{n^{*}+1}$ with $n^{*} \geq 2$, or by $m_{1}>m_{2}=\cdots=m_{n^{*}}>m_{n^{*}+1}$ with $n^{*} \geq 2$, then $\lim _{\gamma \rightarrow 0^{+}} n^{*}(\gamma)=n^{*}$

b) $\lim _{\gamma \rightarrow 0^{+}} x_{i}^{k^{*}}(\gamma)= \begin{cases}\frac{\left(n^{*}-1\right) v_{i}^{k}}{n^{* 2} m_{i}}, & m_{1}=m_{2}=m_{i}=\cdots=m_{n^{*}} \\ 0, & m_{1}>m_{2}=m_{i}=\cdots=m_{n^{*}} \\ 0, & m_{i}>m_{2} \geq \ldots\end{cases}$

\footnotetext{
${ }^{6}$ In this latter case we get multiple equilibria if $\gamma=1$ with the property that the sum of contributions is always identical (Baik, 2008). In this sense, our convergence result can be interpreted as an equilibrium-selection mechanism by focussing on the equal-contribution equilibrium.
} 
c) $\lim _{\gamma \rightarrow 0^{+}} \frac{x_{i}^{k^{*}}(\gamma)}{X_{i}^{*}(\gamma)}=\frac{\left(v_{i}^{k}\right)}{\sum_{l}\left(v_{i}^{l}\right)}$

d) $\lim _{\gamma \rightarrow 0^{+}} Q^{*}(\gamma)= \begin{cases}\infty, & \forall j: m_{j}>1 \\ \frac{n^{*}(\gamma)-1}{\sum_{j=1}^{n^{*}} \frac{1}{v_{j}^{1}}}, & m_{1}=\cdots=m_{n^{*}}=1 \\ \frac{n^{*}(\gamma)-1}{\sum_{j=2}^{n^{*}} \frac{1}{v_{j}^{1}}}, & m_{1}>m_{2}=\cdots=m_{n^{*}}=1\end{cases}$

e) $\lim _{\gamma \rightarrow 0^{+}} \frac{Q_{i}^{*}(\gamma)}{Q^{*}(\gamma)}= \begin{cases}=0, & m_{1}>m_{i} \\ =1 / n^{*}, & m_{1}=m_{i}=\cdots=m_{n^{*}} . \\ =1, & m_{i}>m_{2} \geq \ldots\end{cases}$

Proposition 5. Suppose $\forall i: m_{i} \leq m_{i+1}$. For $\gamma \rightarrow 0^{-}$, we obtain:

a) If $n^{*}$ is either defined by $m_{1}=\cdots=m_{n^{*}}<m_{n^{*}+1}$ with $n^{*} \geq 2$, or by $m_{1}<m_{2}=\cdots=m_{n^{*}}<m_{n^{*}+1}$ with $n^{*} \geq 2$, then $\lim _{\gamma \rightarrow 0^{+}} n^{*}(\gamma)=n^{*}$

b) $\lim _{\gamma \rightarrow 0^{-}} x_{i}^{k^{*}}(\gamma)= \begin{cases}\frac{\left(n^{*}-1\right) v_{i}^{k}}{n^{* 2} m_{i}}, & m_{1}=m_{2}=m_{i}=\cdots=m_{n^{*}} \\ 0, & m_{1}<m_{2}=m_{i}=\cdots=m_{n^{*}} \\ 0, & m_{i}<m_{2} \geq \ldots\end{cases}$

c) $\lim _{\gamma \rightarrow 0^{-}} \frac{x_{i}^{k^{*}}(\gamma)}{X_{i}^{*}(\gamma)}=\frac{\left(v_{i}^{k}\right)}{\sum_{l}\left(v_{i}^{l}\right)}$

d) $\lim _{\gamma \rightarrow 0^{-}} Q^{*}= \begin{cases}0, & m_{2}>1 \\ \frac{n^{*}(\gamma)-1}{\sum_{j=1}^{n^{*}} \frac{1}{v_{j}^{1}}}, & m_{1}=\cdots=m_{n^{*}}=1\end{cases}$

e) $\lim _{\gamma \rightarrow 0^{-}} \frac{Q_{1}^{*}}{Q^{*}}= \begin{cases}=0, & m_{1}>m_{i} \\ =1 / n^{*}, & m_{1}=m_{i}=\cdots=m_{n^{*}} . \\ =1, & m_{i}<m_{2} \geq \ldots\end{cases}$

The proofs to these two propositions can be found in the appendix. In part a) of each proposition the participating groups are defined. For $\gamma \rightarrow 0^{+}$, only the largest, while for $\gamma \rightarrow 0^{-}$, only the smallest groups participate in the contest (in both cases there always remain at least two groups). Unless there exist groups with equal sizes (which are maximal for the convergence from above, and minimal for the convergence from below), individual efforts always approach zero. Further, e) shows the winning probabilities of the groups: the largest (respectively smallest for convergence from below) groups have equal probabilities of winning, while any group smaller (larger) has zero probability of winning in equilibrium, d) tells us that and $Q^{*}(\gamma)$ converges to infinity if $\gamma$ converges from above and there is no group of size 1 which participates 
in the contest. These results show that the behavior around $\gamma=0$ is crucially determined by the relative size of the groups. This property has a resemblance to the results on the so-called "group-size paradox", i.e. the apparent disadvantage of larger groups compared to smaller ones (Esteban \& Ray, 2001; Olson, 1965). To obtain a proper intuition for this resemblance it is helpful to return to Example 2.

Example 2 continued: Coming back to Example 2 from Section 3, (5) can be used to determine that the values of the impact functions are

$$
q_{1}\left(m_{1}, m_{2}, \gamma, v\right)=v \frac{m_{1}^{\frac{1-\gamma}{\gamma}} m_{2}^{\frac{1-\gamma}{\gamma}}}{\left(m_{1}^{\frac{1-\gamma}{\gamma}}+m_{2}^{\frac{1-\gamma}{\gamma}}\right)^{2}}, \quad q_{2}\left(m_{1}, m_{2}, \gamma, v\right)=v \frac{m_{1}^{\frac{1-\gamma}{\gamma}} m_{2}^{\frac{1-\gamma}{\gamma}}}{\left(m_{1}^{\frac{1-\gamma}{\gamma}}+m_{2}^{\frac{1-\gamma}{\gamma}}\right)^{2}},
$$

which in turn can be used to determine the equilibrium winning probabilities:

$$
p_{1}\left(m_{1}, m_{2}, \gamma\right)=\frac{m_{2}^{\frac{\gamma-1}{\gamma}}}{m_{1}^{\frac{\gamma-1}{\gamma}}+m_{2}^{\frac{\gamma-1}{\gamma}}}, \quad p_{2}\left(m_{1}, m_{2}, \gamma\right)=\frac{m_{1}^{\frac{\gamma-1}{\gamma}}}{m_{1}^{\frac{\gamma-1}{\gamma}}+m_{2}^{\frac{\gamma-1}{\gamma}}} .
$$

It follows from Proposition 3 that the limit behavior of these probabilities is

$$
\begin{aligned}
& \lim _{\gamma \rightarrow 0^{-}} p_{1}\left(m_{1}, m_{2}, \gamma\right)=\left\{\begin{array}{ll}
1, & m_{1}<m_{2} \\
0, & m_{1}>m_{2}
\end{array},\right. \\
& \lim _{\gamma \rightarrow 0^{+}} p_{1}\left(m_{1}, m_{2}, \gamma\right)=\left\{\begin{array}{ll}
0, & m_{1}<m_{2} \\
1, & m_{1}>m_{2}
\end{array},\right.
\end{aligned}
$$

and analogously for $p_{2}\left(m_{1}, m_{2}, \gamma\right)$. Figure 1 shows $p_{1}\left(m_{1}, m_{2}, \gamma\right)$ (dashed line) and $p_{2}\left(m_{1}, m_{2}, \gamma\right)$ (solid line) for the case $m_{1}>m_{2}$. We will focus on $p_{1}\left(m_{1}, m_{2}, \gamma\right)$ in the following. The graph starts at 0.5 at $\gamma=1$. This is the well-known case where group size has no impact on the winning probability (Baik, 2008). $p_{1}\left(m_{1}, m_{2}, \gamma\right)$ steadily rises to 1 as $\gamma$ converges to 0 . At this point it jumps to 0 and increases to 0.5 again as $\gamma$ converges to $-\infty$. In this case, group-size again does not matter because only the minimum contribution counts (Lee, 2008). In order to understand the economic intuition for this result, it makes sense to highlight the similarity of our problem to the problem analyzed by Esteban and Ray (2001). They found that the group-size paradox need not hold in a contest-environment and may be reversed to yield an advantage for large groups if the costs of effort are sufficiently convex. This result has a counterpart in our model if $\gamma \in(0,1)$. Reducing $\gamma$ in this interval increasingly improves the position of the larger group. In the limit, the larger group can win the contest with probability close to one as $\gamma$ approaches zero. A reduction 


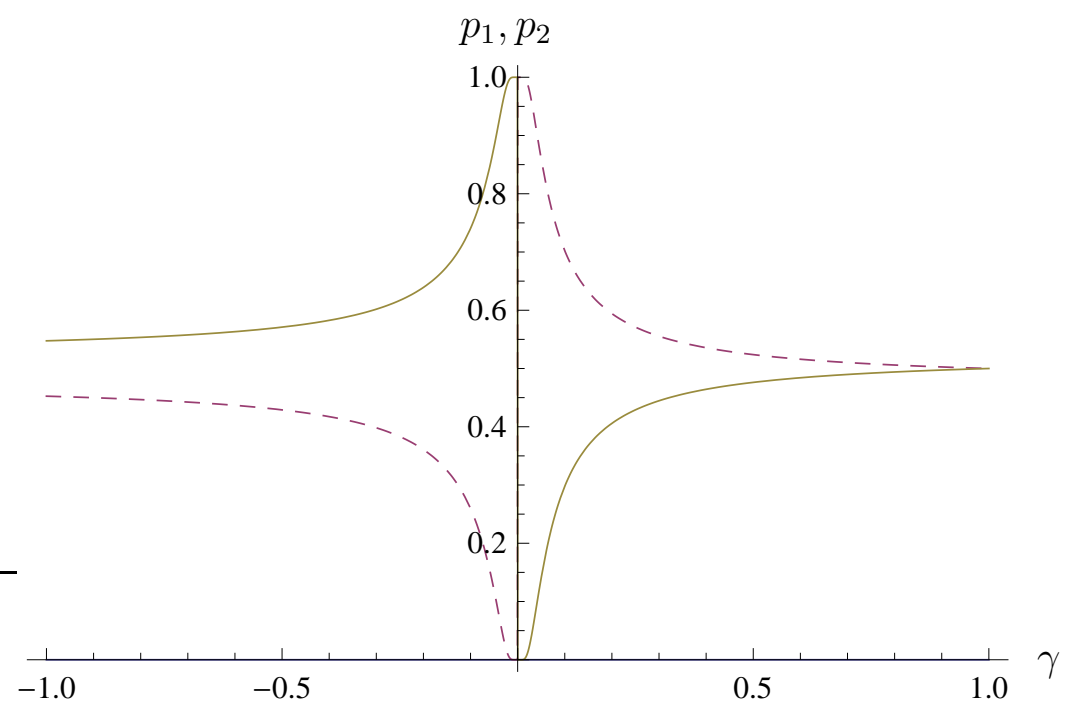

Figure 1: Equilibrium probabilities for different values of $\gamma\left(m_{1}=11, m_{2}=10\right)$.
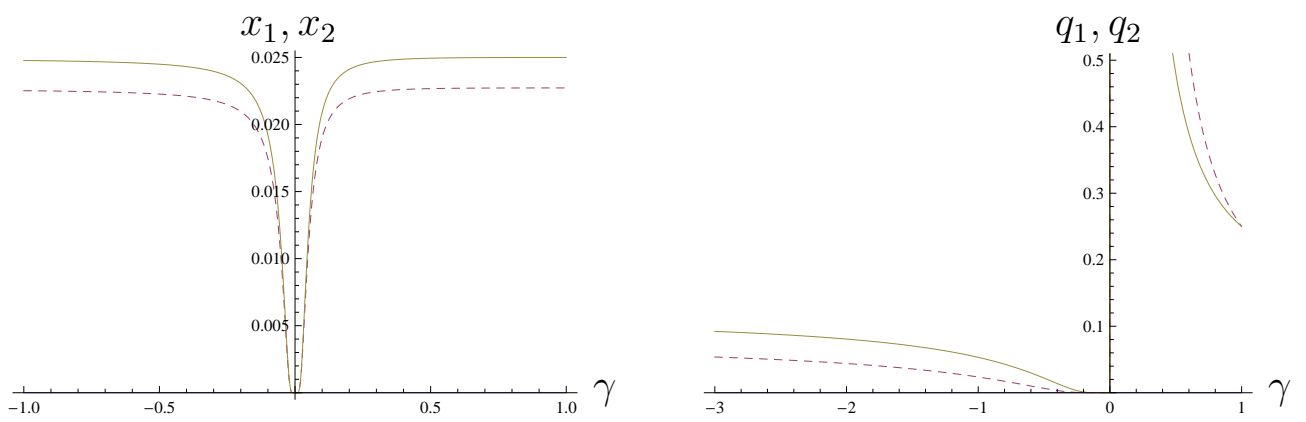

Figure 2: Effort levels (left) and impacts (right) for different values of $\gamma$.

in the elasticity of substitution has a similar effect as an increase in the convexity of the costs-of effort function. Interestingly, if $\gamma<0$, the smaller group starts with an advantage as $\gamma \rightarrow 0^{-}$, but reducing $\gamma$ again has the same effect. In this case, the group-size paradox does not only exist but is intensified by the technological properties of the impact function. Hence, a steady change in $\gamma$ at 0 has a dramatic influence on the outcome of the game if the impact functions are of the CES form. To better understand this property it makes sense to have a closer look at (5).

The left panel of Figure 2 shows $x_{1}\left(m_{1}, m_{2}, \gamma, v\right)$ and $x_{2}\left(m_{1}, m_{2}, \gamma, v\right)$ as functions of $\gamma$ for $m_{1}>m_{2}$. The dashed graph is $x_{1}\left(m_{1}, m_{2}, \gamma, v\right)$ and the solid graph is $x_{2}\left(m_{1}, m_{2}, \gamma, v\right)$. As could have been expected, individuals of the smaller group invest 
more. However, this does not translate into group impact, as can be seen from the right panel of Figure 2. In this figure, the dashed graph is $q_{1}\left(m_{1}, m_{2}, \gamma, v\right)$ and the solid graph is $q_{2}\left(m_{1}, m_{2}, \gamma, v\right)$. First of all, the impact technology translates group $1^{\prime}$ 's efforts into an increasing advantage with respect to impact as $\gamma \rightarrow 0^{+}$. That is, even though individual efforts of group 1 are below those of group 2, $q_{1}>q_{2}$ As soon as $\gamma$ is turning negative, the impact-advantage passes over to group 2. It follows also from Figure 2 that effort converges to zero as $\gamma$ approaches zero. This follows from a specific property of the CES-impact function: If all members of the same group exert identical effort, $q_{i}\left(x_{i}\right)=m_{i}^{1 / \gamma} x_{i}$ holds ${ }^{7}$. The equation shows that in case that $\gamma \rightarrow 0^{+}$the impact of the group increases even if group size and effort remains constant. Hence, effort goes to zero because the groups are becoming infinitely productive. The opposite is true for $\gamma \rightarrow 0^{-}$: the impact of the group decreases even if group size and effort remains constant. Effort goes to zero because the groups are becoming infinitely unproductive. End of Example 2.

If we follow Alchian and Demsetz (1972) and see a certain degree of complementarity in effort as constitutive for a group problem, Proposition 3 and the above discussion have important implications for our perception of the relevance of relative group size. The discussion about the existence of a "small-group advantage" or a "large-group advantage" crucially depends on the degree of complementarity between group-members efforts. Hence, we do not have any a priori reason to believe in the existence of such an advantage.

\subsection{Comparative statics}

We now turn to the comparative-static analysis of the influence of the elasticity of substitution on the behavior in the contest using the approach developed by Cornes and Hartley (2005). Most interestingly, individual valuations in relation to the valuations of the other group members define the individuals' share of the amount of effort spent by the group, $x_{i}^{k^{*}} / X_{i}^{*}$. The valuation of other groups have no effect on these shares. As was to be expected, a larger elasticity of substitution $\gamma$ increases ceteris paribus the dispersion of these shares, since the exponent discriminates more

\footnotetext{
${ }^{7}$ To eliminate this property, one could normalize the impact function such that $q_{i}(\ldots)=$ $\left(\sum\left(x_{i}^{k}\right)^{\gamma}\right)^{1 / \gamma} \cdot m_{i}^{(\gamma-1) / \gamma}$. This however leads to a function that no longer converges to the $\min (\ldots)$ function if $\gamma \rightarrow-\infty$, which we desire here. Such a normalized impact function may however be of interest elsewhere.
} 
strongly between differences in valuations. The next proposition states the effect of $\gamma$ on the individual shares.

\section{Proposition 6.}

$$
\frac{\partial \frac{x_{i}^{k}}{X_{i}}}{\partial \gamma} \gtreqless 0 \Leftrightarrow v_{i}^{k} \gtreqless \prod_{l} v_{i}^{l}\left(\frac{v_{i}^{l} \frac{1}{1-\gamma}}{\sum_{s} v_{i}^{s} \frac{1}{1-\gamma}}\right) .
$$

at a point where the participating groups remain the same.

Proof. Taking the derivative of (11) with respect to $\gamma$ yields

$$
\frac{\partial \frac{x_{i}^{k}}{X_{i}}}{\partial \gamma}=\frac{v_{i}^{k} \frac{1}{1-\gamma}}{\sum_{l} v_{i}^{l \frac{1}{1-\gamma}}} \frac{1}{(1-\gamma)^{2}}\left(\ln v_{i}^{k}-\frac{\sum_{l} v_{i}^{l \frac{1}{1-\gamma}} \ln v_{i}^{l}}{\sum_{l} v_{i}^{l} \frac{1}{1-\gamma}}\right)
$$

The RHS of the above equation is positive whenever the term in brackets is positive. Setting $\ln v_{i}^{k} \geq \sum_{l} v_{i}^{l} \frac{1}{1-\gamma} \ln v_{i}^{l} / \sum_{l} v_{i}^{l \frac{1}{1-\gamma}}$ and rearranging yields the above condition.

The proposition implies that for all group members with a valuation above the weighted geometric mean, the share of total group effort increases with $\gamma$. The result shows that the dispersion of valuations plays a crucial role for the comparative-static effects of $\gamma$. To get a better intuition for this result we return to Example 3 .

Example 3 continued: If the game is symmetric between groups but group members differ in their valuation of the rent, we have seen in (6) that $\gamma$ may influence the behavior in the contest. Figure 3 shows how a change in the within-group dispersion of valuations $v^{\max }-v^{\text {min }} L$ influences behavior, and we have assumed that this change is a mean-preserving spread of the form $d v^{\text {max }}=-d v^{\text {min }}$, where $d v^{\text {max }}, d v^{\text {min }}$ are changes in the valuation of the rent such that the average income of the group remains unchanged. The dashed lines correspond to $v^{\max }$ whereas the solid lines correspond to $v^{\min }$. Lines $A$ and $D$ correspond to a large spread $v^{\max }-v^{\min }$ and lines $B$ and $C$ correspond to a small spread $v^{\max }-v^{\min }$. First of all, the figure shows that as $\gamma$ converges to 1 the equilibrium converges to the Baik (2008) case where only the high-valuation types contribute. In addition, a reduction in the spread $v^{\max }-v^{\min }$ reduces the maximum, which implies that $B$ converges to a smaller value than $A$. At the opposite side, if $\gamma$ converges to $-\infty$, we approximate the result by Lee (2008): Both, $x^{\min }$ and $x^{\max }$ converge to the same value that is determined by the harmonic mean of the valuations in the group. A reduction in the spread of valuations 


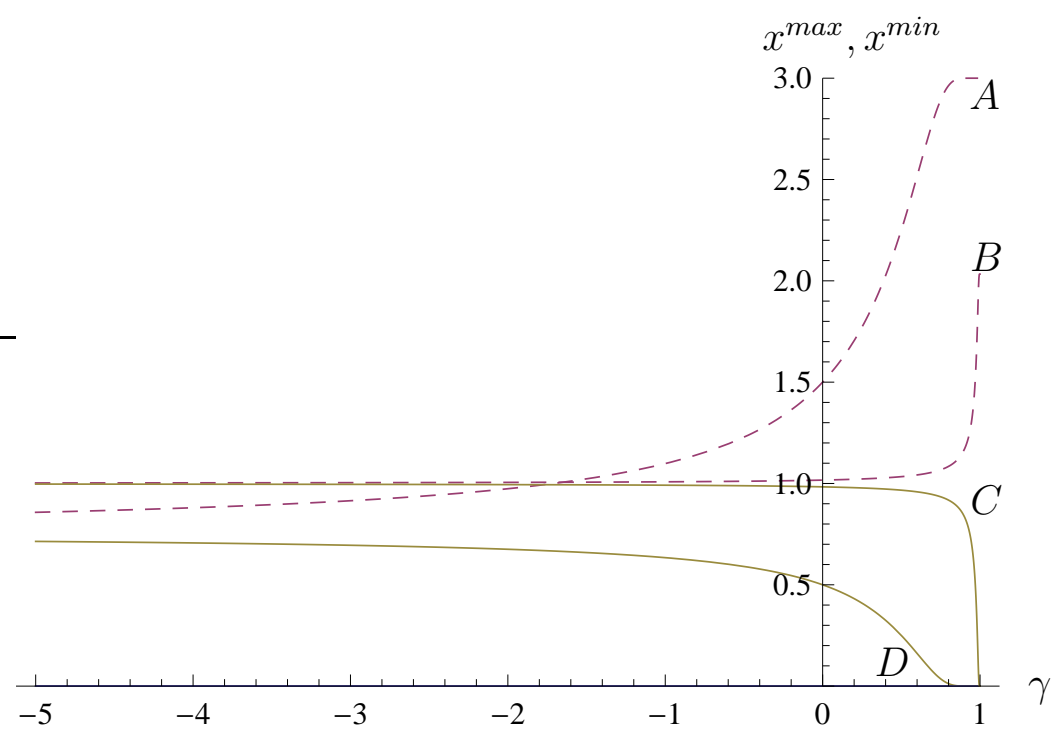

Figure 3: Effort levels for different values of $\gamma$ for a high and a low spread of valuations.

$v^{\max }-v^{\min }$ increases the harmonic mean, which implies that $B$ and $C$ converge to a higher level than $A$ and $D$. For the intermediate values of $\gamma$ we get a steady increase in $x^{\text {max }}$ and a steady decrease in $x^{\text {min }}$ as $\gamma$ increases. In the limit case $v^{\text {max }}=v^{\text {min }}$ this line would be straight. End of Example 3.

It has been impossible to derive general results for the effect of $\gamma$ on winning probabilities $Q_{i}^{*}(\gamma) / Q^{*}(\gamma)$ and the total impact $Q^{*}(\gamma)$. However, it is possible to generate further insight in the important case where all individuals in the same group have the same evaluation $\left(v_{i}^{k}=v_{i}\right)$. This separates the effect of the dispersion of the valuations the group members have from the effect of the group size and the total valuation the group has. The results are summarized in the next proposition.

Proposition 7. Let $\gamma \neq 0$. a) Assume that $v_{i}^{k}=v_{i} \forall i, k$ and $\exists i$ s.t. $m_{i}>1$, then $Q^{*}(\gamma)$ is strictly decreasing in $\gamma$.

b) Assume that $v_{i}^{k}=v \forall i, k$, then

$$
\frac{\partial \frac{Q_{i}^{*}(\gamma)}{Q^{*}(\gamma)}}{\partial \gamma} \gtreqless 0 \Leftrightarrow m_{i} \lesseqgtr \prod_{j} m_{j}^{\left(\frac{m_{j}^{\frac{\gamma-1}{\gamma}}}{\sum_{k} m_{k}^{\frac{\gamma-1}{\gamma}}}\right)} .
$$


c) Assume that $v_{i}^{k}=v_{i} \forall i, k$, then

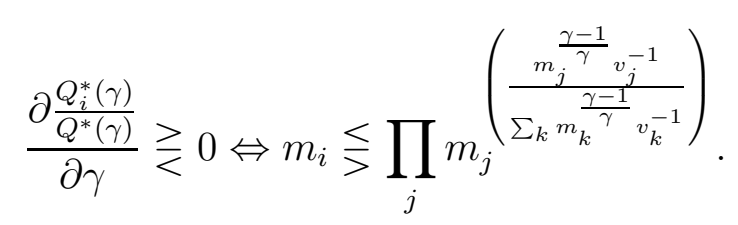

Proof. Taking the derivative of (9) with respect to $\gamma$ where the participating groups remain the same yields:

$$
\frac{\partial Q^{*}(\gamma)}{\partial \gamma}=-\frac{n-1}{\left(\gamma \sum_{j} m_{j}^{\frac{\gamma-1}{\gamma}} v_{j}^{-1}\right)^{2}} \sum_{j} m_{j}^{\frac{\gamma-1}{\gamma}} v_{j}^{-1} \ln m_{j} .
$$

Therefore, for a given set of participating groups, total effort is decreasing in $\gamma$ unless $m_{i}=1 \forall i$. From Lemma 2 we know that total effort is a continuous function in $\gamma$ if $\gamma \neq 0$, that a group that is becoming inactive for some $\gamma$ fades out smoothly. Total effort can thus be expressed as a continuous, piecewise strictly decreasing function, which is a strictly decreasing function as well. Note again that $Q^{*}(\gamma)$ may be discontinuous at $\gamma=0$ and thus the results only hold below and above this discontinuity. This establishes part a) of the proposition.

Similarly, if all individuals within one group are identical $\left(v_{i}^{k}=v_{i}\right)$ it follows for a given $n^{*}$ :

$$
\frac{\partial \frac{Q_{i}^{*}(\gamma)}{Q^{*}(\gamma)}}{\partial \gamma}=-(n-1) \frac{m_{i}^{\frac{\gamma-1}{\gamma}} v_{i}^{-1}}{\left(\gamma \sum_{j} m_{j}^{\frac{\gamma-1}{\gamma}} v_{j}^{-1}\right)^{2}}\left(\sum_{j} m_{j}^{\frac{\gamma-1}{\gamma}} v_{j}^{-1} \ln \frac{m_{i}}{m_{j}}\right),
$$

from which part c) of the proposition can be obtained by the fact that the last term in brackets determines the sign of the total derivative because we again know from Lemma 2 that total effort is a continuous function in $\gamma$ if $\gamma \neq 0$. Setting $v_{i}=v \forall i$ then yields part b).

Part a) of the proposition states that under the assumption that all individuals within each group are identical, the total impact of all groups into the contest success function is decreasing in $\gamma$. For the intuition underlying part b), suppose we make the further simplifying assumption that there are only two groups $i$ and $j$. It follows that $\partial\left(Q_{i}^{*}(\gamma) / Q^{*}(\gamma)\right) / \partial \gamma$ is negative if and only if $m_{i}>m_{j}$ : The free-rider problem is intensified by larger values of $\gamma$ for larger groups. If investments within a group become less complementary, the larger group suffers more from weaker incentives. 
Hence, its relative share of impact and thereby winning probability goes down. This property can be nicely seen in Figure 1 where the winning probability of the larger group is decreasing for all values of $\gamma \neq 0$. The figure and the above analysis also show that this result has to be interpreted with caution because of the potential discontinuity of $p_{i}$ at $\gamma=0$. The same logic carries over to the case of more than two groups. However, the relative standing of group $i$ then depends on the weighted geometric mean of all group sizes, as established in part c) of the proposition.

This intuition is further confirmed by the fact that $\frac{\partial \frac{Q_{i}^{*}(\gamma)}{Q^{*}(\gamma)}}{\partial \gamma}=0$ if $m_{i}=m$ even for differing valuations for all $i$, which follows immediately from c). This corresponds to Corollary 1 and Example 1. In general, c) captures the effect of $\gamma$ if the valuations differ between, but not within groups. The effort share of a homogenous group decreases in $\gamma$ whenever the number of group members is above the valuation-weighted geometric average of group members across all groups.

\section{Concluding Remarks}

This paper has started from the observation that group effort can in general not be additively decomposed into some sum (of functions) of individual efforts. The use of a CES-impact function has allowed to identify the main channels of influence of the elasticity of substitution on the behavior in and the outcome of contests. If groups are of equal size and homogenous (i.e. all group members have the same valuation within the group), the elasticity of substitution does not matter. For heterogenous groups, the higher the complementarity of efforts, the lower the divergence of efforts among group members. As we have seen in Example 3, this does not necessarily lead to an advantage of the group with more diverse valuations. If all groups are homogenous but differ in size and valuations, we were able to state the effect of the elasticity of substitution on the winning probabilities of a group. Except for the discontinuity at the Cobb-Douglas case $(\gamma=0)$, higher complementarity tends to favor large groups. Near the discontinuity, small groups are at an advantage for $\gamma<0$, while for $\gamma>0$, large groups are at an advantage. In both cases, if there is a single largest (smallest) group, their advantage will become infinitely large leading to effort levels converging to zero. Near the cases of perfect complements and perfect substitutes, the equilibrium converges to special cases of the equilibria in Baik (2008) and Lee (2008), respectively. 
The results give a coherent picture about the role of heterogeneity of groups sizes and valuations between group members. However, it is clear that the the assumption of a linear homogenous impact function combined with the assumption of a contest success function that is homogenous of degree zero has greatly simplified the analysis. We are nevertheless confident that our analysis provides some general insights into the relevance of the degree of complementarity of group members' efforts for their behavior in contests.

\section{Appendix A: Proof of Lemma 1}

Proof. We first check that the interior solution is a local maximum. The first-order condition of the maximization problem (2) can be written as

$$
\frac{Q_{/ i}}{Q^{2}} Y_{i}^{\frac{1}{\gamma}-1}=\frac{\left(y_{i}^{k}\right)^{\frac{1}{\gamma}-1}}{v_{i}^{k}} .
$$

The second-order condition is satisfied if

$$
\frac{v_{i}^{k} Q_{/ i} Y_{i}^{\frac{1}{\gamma}-2}}{\gamma Q^{2}}\left(\frac{1-2 \frac{Q_{i}}{Q}}{\gamma}-1\right)-\frac{\frac{1}{\gamma}-1}{\gamma}\left(y_{i}^{k}\right)^{\frac{1}{\gamma}-2}<0 .
$$

Solving the first-order condition for $v_{i}^{k}$ and inserting the expression into the secondorder condition we obtain, upon rearranging:

$$
\frac{1-\frac{1}{\gamma}}{\gamma}\left(1-\frac{y_{i}^{k}}{Y_{i}}\right)-2 \frac{1}{\gamma^{2}} \frac{Q_{i} y_{i}^{k}}{Q Y_{i}}<0,
$$

which holds for all $\gamma \in(-\infty, 1)$. Therefore, all solutions of the first-order condition are local maxima taking the other players' strategies as given. The best responses are either given by the solution to the first-order condition, or by a corner solution. From equation (1) it is clear that the only possible corner solutions are non-participation with $x_{i}^{k}=0$. We thus need to verify that whenever the best response of one member of the group is given by the solution to the first-order condition, it is not possible for any member of the group to have the best response $x_{i}^{k}=0$. First, we will show that whenever there exists a solution of the first-order condition for one individual of a group, it exists for all individuals: From the first-order conditions of two representative group members $l, k$ we obtain the within-group equilibrium condition:

$$
\forall l, k<m_{i}: \frac{\left(y_{i}^{k}\right)^{\frac{1}{\gamma}-1}}{v_{i}^{k}}=\frac{\left(y_{i}^{l}\right)^{\frac{1}{\gamma}-1}}{v_{i}^{l}}
$$


for all members $k, l$ of group $i$. Both, the left-hand side (LHS) and right-hand side (RHS) of (A.4) are strictly increasing in $y_{i}^{k}, y_{i}^{l}$ if $\gamma \in(0,1)$. For $\gamma \in(-\infty, 0)$ both LHS and RHS of (A.4) are strictly decreasing in $y_{i}^{k}, y_{i}^{l}$. Thus, for each $y_{i}^{k}$ there exists a $y_{i}^{l}$ such that the within-group equilibrium condition holds. Since for all group members the LHS of (A.1) is equal, there exists a positive solution to the first-order condition (FOC) for either all group members or none.

Second, we need to show that $x_{i}^{k}=0$ is not a best response if it is a best response for another individual $l$ in the group to play $x_{i}^{l}>0$. We do so by contradiction: Obviously, for a corner solution with $x_{i}^{k}=0$ and $x_{i}^{l}>0$ the following condition needs to hold:

$$
\frac{\partial \pi_{i}^{k}}{\partial x_{i}^{k}}=\frac{Q / i}{Q^{2}} Y_{i}^{\frac{1}{\gamma}-1}\left(x_{i}^{k}\right)^{\gamma-1} v_{i}^{k}-\left.1\right|_{x_{i}^{k}=0, x_{i}^{l}>0} \leq 0 .
$$

From the fact that there is an individual $l$ in the group, which participates with strictly positive effort, we know that

$$
\frac{\partial \pi_{i}^{l}}{\partial x_{i}^{l}}=\frac{Q_{/ i}}{Q^{2}} Y_{i}^{\frac{1}{\gamma}-1}\left(x_{i}^{l}\right)^{\gamma-1} v_{i}^{l}-\left.1\right|_{x_{i}^{k}=0, x_{i}^{l}>0}=0
$$

Inserting (A.6) into (A.5) yields:

$$
\frac{\left(x_{i}^{l}\right)^{1-\gamma}}{v_{i}^{l}}-\left.\frac{\left(x_{i}^{k}\right)^{1-\gamma}}{v_{i}^{k}}\right|_{x_{i}^{k}=0, x_{i}^{l}>0} \leq 0
$$

from which we obtain by inserting $x_{i}^{k}=0$ :

$$
\left.\left(x_{i}^{l}\right)^{1-\gamma}\right|_{x_{i}^{l}>0} \leq 0
$$

which is a contradiction for all $\gamma<1$. Thus there does not exist an equilibrium in which for one player in the group a corner solution at zero effort investments is obtained while for another an interior solution holds. 


\section{Appendix B: Proof of Lemma 2}

Proof. If there exists a solution to the FOC, it is characterized by the following equation, obtained by solving (A.4) for $y_{i}^{l}$ and summing over all $l$,

$$
Y_{i}=y_{i}^{k} \sum_{l}\left(\frac{v_{i}^{l}}{v_{i}^{k}}\right)^{\frac{\gamma}{1-\gamma}} .
$$

We can now solve equation (A.1) for $Y_{i}$ explicitly:

$$
Y_{i}=\left(\sqrt{Q_{/ i} V_{i}(\gamma)}-Q_{/ i}\right)^{\gamma}
$$

Thus, the condition for a strictly interior solution is $\left(\sum_{l} v_{i}^{l \frac{\gamma}{1-\gamma}}\right)^{\frac{1-\gamma}{\gamma}}>Q_{/ i}$. Note that this condition is the same for all members of a group. In all other cases, we get $y_{i}^{k}=0$ for $\gamma \in(0,1)$ and $y_{i}^{k}=\infty$ for $\gamma \in(-\infty, 0)$ as was to be expected and which corresponds to $x_{i}^{k}=0$. In these cases we have $\forall l: y_{i}^{k}=y_{i}^{l}$ by equation (A.4) and by the definition of $Q_{i}$, we have: $Q_{i}=Y_{i}^{\frac{1}{\gamma}}=0$. We can write a group best-response function as

$$
\hat{Q}_{i}\left(\gamma, Q_{/ i}\right)=\max \left(0, \sqrt{Q_{/ i} V_{i}(\gamma)}-Q_{/ i}\right) .
$$

establishing part a), since by Lemma 1 either for all group members we obtain an interior solution or for none. Since the best-response function is continuous in $\gamma \neq 0$ and in the strategies of the other groups $Q_{/ i}$, if a unique Nash equilibrium exists, the equilibrium strategies must also be continuous in $\gamma$. This establishes part c) of Lemma 2. What remains to be shown is which groups participate in equilibrium. Suppose a group $\zeta$ participates in equilibrium with strictly positive effort, while a group $\zeta+1$ does not participate. Let $Q_{i}^{*}(\gamma)$ be $Q_{i}$ in equilibrium (we ignore here that these are best responses and should thus be functions of $Q_{/ i}^{*}$ ) and let the other variables introduced above be defined correspondingly in equilibrium. Then by the above condition in equilibrium we have for any given $\gamma$ :

$$
\begin{gathered}
V_{\zeta}(\gamma)>Q_{/ \zeta}^{*}(\gamma) \\
V_{\zeta+1}(\gamma) \leq Q_{/ \zeta+1}^{*}(\gamma)
\end{gathered}
$$

Since by assumption $Q_{\zeta+1}^{*}(\gamma)=0$, we have $Q_{/ \zeta+1}^{*}(\gamma)=Q^{*}(\gamma)$. Solving $(7)$ for $Q_{/ i}$ tells us that in an equilibrium where group $\zeta$ participates, the following needs to be true:

$$
Q_{/ \zeta}^{*}(\gamma)=\frac{Q^{*}(\gamma)^{2}}{V_{\zeta}(\gamma)}
$$


We now insert (B.5) into the first equation of (B.4) and the condition $\hat{Q}_{/ \zeta+1}=\hat{Q}$ into the second equation. Thus the condition (B.4) becomes

$$
\begin{array}{r}
V_{p}(\gamma)>Q^{*}(\gamma) \\
V_{\zeta+1}(\gamma) \leq Q^{*}(\gamma)
\end{array}
$$

in equilibrium. It follows that $V_{\zeta}(\gamma)>V_{\zeta+1}(\gamma)$. We can thus order the groups such that $V_{i}(\gamma) \geq V_{i+1}(\gamma)$ and define $n^{*}(\gamma)$ as the group with the highest index number that still participates with strictly positive effort. By (B.6), all groups $i \leq n^{*}(\gamma)$ participate. This establishes part b) of Lemma 2 .

\section{Appendix C: Proof of Proposition 5}

Proof. We will make use of the following results:

$$
\begin{gathered}
\lim _{\gamma \rightarrow 0^{+}} V_{i}^{\frac{\gamma}{1-\gamma}}=\lim _{\gamma \rightarrow 0^{+}} \sum_{l}\left(v_{i}^{l}\right)^{\frac{1}{(1 / \gamma)-1}}=m_{i} \\
\lim _{\gamma \rightarrow 0^{+}} V_{i}(\gamma)=\lim _{\gamma \rightarrow 0^{+}}\left(\sum_{l}\left(v_{i}^{l}\right)^{\frac{1}{(1 / \gamma)-1}}\right)^{(1 / \gamma)-1}= \begin{cases}\infty, & m_{i}>1 \\
v_{i}^{k} & m_{i}=1\end{cases}
\end{gathered}
$$

Further,

$$
\begin{aligned}
\lim _{\gamma \rightarrow 0^{+}} \frac{Q_{i}^{*}(\gamma)}{Q^{*} \gamma}= & \lim _{\gamma \rightarrow 0^{+}} 1-\frac{n^{*}(\gamma)-1}{1+\sum_{j \neq i} \frac{V_{i}}{V_{j}}} \\
= & \lim _{\gamma \rightarrow 0^{+}} 1-\frac{n^{*}(\gamma)-1}{1+\sum_{j \neq i}\left(\frac{m_{i}}{m_{j}}\right)^{\frac{1-\gamma}{\gamma}}} \\
& \begin{cases}<0, & m_{i}=\min _{j}\left(m_{j}\right), m_{i}<m_{2} \\
=0, & m_{1}>m_{i} \geq m_{j}, \forall j \\
=1 / n^{*}, & m_{1}=m_{i}=\cdots=m_{n^{*}} \\
=1, & m_{i}>m_{2} \geq \cdots\end{cases}
\end{aligned}
$$

Note that by the first case all groups who do not have at least a group size equal to the second largest group will not participate for a sufficiently small $\gamma$. This is because for $\gamma$ decreasing towards 0, iteratively all groups with minimal size will drop out of the contest. Thus, we have part a) of the proposition. For the case that 
there are $n^{*}-1$ participating groups of equal size strictly smaller than the largest group, their winning probability converges to zero (and thus for the largest group to one). For the case of $n^{*}$ equal groups with maximal size it approaches $1 / n^{*}$. This establishes part e).

Suppose now we are at a $\gamma$ small enough, such that only the groups with size $m_{i} \geq m_{2}$ participate in the contest. Then if $m_{1}=m_{2}=m_{i}=\cdots=m_{n^{*}}$, we have:

$$
\lim _{\gamma \rightarrow 0^{+}} \frac{Q^{*}(\gamma)}{V_{i}^{\frac{1}{1-\gamma}}}=\frac{n^{*}-1}{n^{*}\left(\frac{\left(m_{i}\right)^{1 /(1-\gamma)}}{m_{i}}\right)^{\frac{1-\gamma}{\gamma}}}=\frac{n^{*}-1}{n^{*} \cdot m_{i}} .
$$

If $m_{1}>m_{2}=m_{i}=\cdots=m_{n^{*}}$, we have:

$\lim _{\gamma \rightarrow 0^{+}} \frac{Q^{*}(\gamma)}{V_{i}^{\frac{1}{1-\gamma}}}=\frac{n^{*}-1}{\left(\frac{\left(m_{i}\right)^{1 /(1-\gamma)}}{m_{1}}\right)^{1 / \gamma-1}+\left(n^{*}-1\right) \cdot\left(\frac{\left(m_{i}\right)^{1 /(1-\gamma)}}{m_{i}}\right)^{1 / \gamma-1}}=\frac{n^{*}-1}{0+\left(n^{*}-1\right) m_{i}}=\frac{1}{m_{i}}$.

Finally, for the largest group, if $m_{i}>m_{2} \geq \ldots$, we have:

$$
\lim _{\gamma \rightarrow 0^{+}} \frac{Q^{*}(\gamma)}{V_{i}^{\frac{1}{1-\gamma}}}=\frac{n^{*}-1}{m_{i}+\left(n^{*}-1\right) \cdot \infty}=0
$$

Further, $\lim _{\gamma \rightarrow 0^{+}}\left(v_{i}^{k}\right)^{\frac{1}{1-\gamma}}=v_{i}^{k}$. Putting the results together, we have:

$$
\begin{aligned}
\lim _{\gamma \rightarrow 0^{+}} x_{i}^{k}= & \begin{cases}\frac{n^{*}-1}{n^{*} \cdot m_{i}} \cdot 1 / n^{*} \cdot v_{i}^{k}, & m_{1}=m_{2}=m_{i}=\cdots=m_{n^{*}} \\
\frac{1}{m_{i}} \cdot 0 \cdot v_{i}^{k}, & m_{1}>m_{2}=m_{i}=\cdots=m_{n^{*}}, \\
0 \cdot 1 \cdot v_{i}^{k}, & m_{i}>m_{2} \geq \cdots\end{cases} \\
= & \begin{cases}\frac{\left(n^{*}-1\right) v_{i}^{k}}{n^{* 2} m_{i}}, & m_{1}=m_{2}=m_{i}=\cdots=m_{n^{*}} \\
0, & m_{1}>m_{2}=m_{i}=\cdots=m_{n^{*}}, \\
0, & m_{i}>m_{2} \geq \ldots\end{cases}
\end{aligned}
$$

which establishes part b).

Given this result, it directly follows from (C.2) and (C.9):

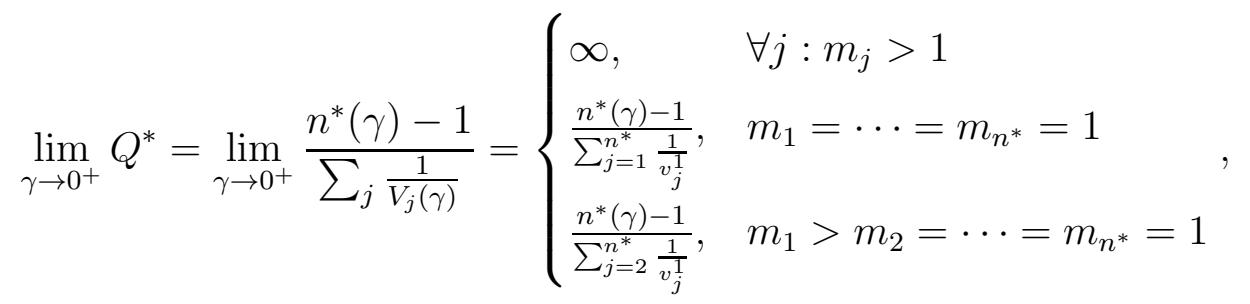

which establishes part d) of the proposition. 


\section{Appendix D: Proof of Proposition 6}

Proof. The proof is in its structure almost identical to the one for Proposition 4 and will thus not be stated here. ${ }^{8}$ Note that

$$
\begin{aligned}
\lim _{\gamma \rightarrow 0^{+}} V_{i}=\lim _{\gamma \rightarrow 0^{+}}\left(\sum_{l}\left(v_{i}^{l}\right)^{\frac{1}{(1 / \gamma)-1}}\right)^{\frac{1}{\gamma}-1} & \\
& = \begin{cases}\left(\frac{1}{m_{i}}\right)^{\frac{1}{0}-1} & m_{i}>1, \\
v_{i}^{1}, m_{i}=1\end{cases} \\
& = \begin{cases}0, & m_{i}>1 \\
v_{i}^{1}, & m_{i}=1\end{cases}
\end{aligned}
$$

which explains intuitively, why the results are reversed such that groups with small group sizes participate only and $\lim _{\gamma \rightarrow 0^{-}} Q^{*}(\gamma)=0$.

\footnotetext{
${ }^{8} \mathrm{~A}$ complete proof can, of course, be obtained from the authors upon request.
} 


\section{References}

Alchian, A. A., \& Demsetz, H. (1972). Information costs, and economic organization. The American Economic Review, 62(5), 777-795.

Baik, K. H. (1993). Effort levels in contests: The public-good prize case. Economics Letters, $41(4), 363-367$.

Baik, K. H. (2008). Contests with group-specific public goods prizes. Social Choice and Welfare, 30(1), 103-117.

Corchón, L. C. (2007). The theory of contests: A survey. Review of Economic Design, 11(2), 69-100.

Cornes, R., \& Hartley, R. (2005). Asymmetric contests with general technologies. Economic Theory, 26(4), 923-946.

Epstein, G. S., \& Mealem, Y. (2009). Group specific public goods, orchestration of interest groups with free riding. Public Choice, 139(3), 357-369.

Esteban, J., \& Ray, D. (2001). Collective action and the group paradox. American Political Science Review, 95(3), 663-672.

Garfinkel, M. R., \& Skaperdas, S. (2007). Chapter 22 economics of conflict: An overview. In T. Sandler \& K. Hartley (Eds.), Handbook of defense economics - defense in a globalized world (Vol. 2, p. 649 - 709). Elsevier.

Hillman, A. L., \& Riley, J. G. (1987). Politically contestable rents and transfers. Economics and Politics, 1(1), 17-39.

Hirshleifer, J. (1983). From weakest-link to best-shot: The voluntary provision of public goods. Public Choice, 41(3), 371-386.

Katz, E., Nitzan, S., \& Rosenberg, J. (1990). Rent-seeking for pure public goods. Public Choice, 65(1), 49-60.

Konrad, K. (2009). Strategy and dynamics in contests. Oxford, UK: Oxford University Press.

Lee, D. (2008). Weakest-link contests with group-specific public good prizes. (Working Paper, Virginia Polytechnic Institute and State University)

Münster, J. (2009). Group contest success functions. Economic Theory, 41(2), 345-357.

Nitzan, S. (1991a). Collective rent dissipation. , 101 (409), 1522-1534.

Nitzan, S. (1991b). Rent-seeking with non-identical sharing rules. Public Choice, $71(1), 43-50$. 
Nitzan, S., \& Ueda, K. (2009). Collective contests for commons and club goods. Journal of Public Economics, $93(1), 48-55$.

Olson, M. (1965). The logic of collective action. Cambridge, MA: Harvard University Press.

Stein, W. E. (2002). Asymmetric rent-seeking with more than two contestants. Public Choice, 113(3), 325-336. 


\section{CESifo Working Paper Series}

for full list see www.cesifo-group.org/wp

(address: Poschingerstr. 5, 81679 Munich, Germany, office@cesifo.de)

3073 Marcel Boyer and Donatella Porrini, Optimal Liability Sharing and Court Errors: An Exploratory Analysis, June 2010

3074 Guglielmo Maria Caporale, Roman Matousek and Chris Stewart, EU Banks Rating Assignments: Is there Heterogeneity between New and Old Member Countries? June 2010

3075 Assaf Razin and Efraim Sadka, Fiscal and Migration Competition, June 2010

3076 Shafik Hebous, Martin Ruf and Alfons Weichenrieder, The Effects of Taxation on the Location Decision of Multinational Firms: M\&A vs. Greenfield Investments, June 2010

3077 Alessandro Cigno, How to Deal with Covert Child Labour, and Give Children an Effective Education, in a Poor Developing Country: An Optimal Taxation Problem with Moral Hazard, June 2010

3078 Bruno S. Frey and Lasse Steiner, World Heritage List: Does it Make Sense?, June 2010

3079 Henning Bohn, The Economic Consequences of Rising U.S. Government Debt: Privileges at Risk, June 2010

3080 Rebeca Jiménez-Rodriguez, Amalia Morales-Zumaquero and Balázs Égert, The VARying Effect of Foreign Shocks in Central and Eastern Europe, June 2010

3081 Stephane Dees, M. Hashem Pesaran, L. Vanessa Smith and Ron P. Smith, Supply, Demand and Monetary Policy Shocks in a Multi-Country New Keynesian Model, June 2010

3082 Sara Amoroso, Peter Kort, Bertrand Melenberg, Joseph Plasmans and Mark Vancauteren, Firm Level Productivity under Imperfect Competition in Output and Labor Markets, June 2010

3083 Thomas Eichner and Rüdiger Pethig, International Carbon Emissions Trading and Strategic Incentives to Subsidize Green Energy, June 2010

3084 Henri Fraisse, Labour Disputes and the Game of Legal Representation, June 2010

3085 Andrzej Baniak and Peter Grajzl, Interjurisdictional Linkages and the Scope for Interventionist Legal Harmonization, June 2010

3086 Oliver Falck and Ludger Woessmann, School Competition and Students' Entrepreneurial Intentions: International Evidence Using Historical Catholic Roots of Private Schooling, June 2010 
3087 Bernd Hayo and Stefan Voigt, Determinants of Constitutional Change: Why do Countries Change their Form of Government?, June 2010

3088 Momi Dahan and Michel Strawczynski, Fiscal Rules and Composition Bias in OECD Countries, June 2010

3089 Marcel Fratzscher and Julien Reynaud, IMF Surveillance and Financial Markets - A Political Economy Analysis, June 2010

3090 Michel Beine, Elisabetta Lodigiani and Robert Vermeulen, Remittances and Financial Openness, June 2010

3091 Sebastian Kube and Christian Traxler, The Interaction of Legal and Social Norm Enforcement, June 2010

3092 Volker Grossmann, Thomas M. Steger and Timo Trimborn, Quantifying Optimal Growth Policy, June 2010

3093 Huw David Dixon, A Unified Framework for Using Micro-Data to Compare Dynamic Wage and Price Setting Models, June 2010

3094 Helmuth Cremer, Firouz Gahvari and Pierre Pestieau, Accidental Bequests: A Curse for the Rich and a Boon for the Poor, June 2010

3095 Frank Lichtenberg, The Contribution of Pharmaceutical Innovation to Longevity Growth in Germany and France, June 2010

3096 Simon P. Anderson, Øystein Foros and Hans Jarle Kind, Hotelling Competition with Multi-Purchasing: Time Magazine, Newsweek, or both?, June 2010

3097 Assar Lindbeck and Mats Persson, A Continuous Theory of Income Insurance, June 2010

3098 Thomas Moutos and Christos Tsitsikas, Whither Public Interest: The Case of Greece's Public Finance, June 2010

3099 Thomas Eichner and Thorsten Upmann, Labor Markets and Capital Tax Competition, June 2010

3100 Massimo Bordignon and Santino Piazza, Who do you Blame in Local Finance? An Analysis of Municipal Financing in Italy, June 2010

3101 Kyriakos C. Neanidis, Financial Dollarization and European Union Membership, June 2010

3102 Maela Giofré, Investor Protection and Foreign Stakeholders, June 2010

3103 Andrea F. Presbitero and Alberto Zazzaro, Competition and Relationship Lending: Friends or Foes?, June 2010 
3104 Dan Anderberg and $\mathrm{Yu}$ Zhu, The Effect of Education on Martial Status and Partner Characteristics: Evidence from the UK, June 2010

3105 Hendrik Jürges, Eberhard Kruk and Steffen Reinhold, The Effect of Compulsory Schooling on Health - Evidence from Biomarkers, June 2010

3106 Alessandro Gambini and Alberto Zazzaro, Long-Lasting Bank Relationships and Growth of Firms, June 2010

3107 Jenny E. Ligthart and Gerard C. van der Meijden, Coordinated Tax-Tariff Reforms, Informality, and Welfare Distribution, June 2010

3108 Vilen Lipatov and Alfons Weichenrieder, Optimal Income Taxation with Tax Competition, June 2010

3109 Malte Mosel, Competition, Imitation, and R\&D Productivity in a Growth Model with Sector-Specific Patent Protection, June 2010

3110 Balázs Égert, Catching-up and Inflation in Europe: Balassa-Samuelson, Engel's Law and other Culprits, June 2010

3111 Johannes Metzler and Ludger Woessmann, The Impact of Teacher Subject Knowledge on Student Achievement: Evidence from Within-Teacher Within-Student Variation, June 2010

3112 Leif Danziger, Uniform and Nonuniform Staggering of Wage Contracts, July 2010

3113 Wolfgang Buchholz and Wolfgang Peters, Equity as a Prerequisite for Stable Cooperation in a Public-Good Economy - The Core Revisited, July 2010

3114 Panu Poutvaara and Olli Ropponen, School Shootings and Student Performance, July 2010

3115 John Beirne, Guglielmo Maria Caporale and Nicola Spagnolo, Liquidity Risk, Credit Risk and the Overnight Interest Rate Spread: A Stochastic Volatility Modelling Approach, July 2010

3116 M. Hashem Pesaran, Predictability of Asset Returns and the Efficient Market Hypothesis, July 2010

3117 Dorothee Crayen, Christa Hainz and Christiane Ströh de Martínez, Remittances, Banking Status and the Usage of Insurance Schemes, July 2010

3118 Eric O’N. Fisher, Heckscher-Ohlin Theory when Countries have Different Technologies, July 2010

3119 Huw Dixon and Hervé Le Bihan, Generalized Taylor and Generalized Calvo Price and Wage-Setting: Micro Evidence with Macro Implications, July 2010 
3120 Laszlo Goerke and Markus Pannenberg, 'Take it or Go to Court' - The Impact of Sec. 1a of the German Protection against Dismissal Act on Severance Payments -, July 2010

3121 Robert S. Chirinko and Daniel J. Wilson, Can Lower Tax Rates be Bought? Business Rent-Seeking and Tax Competition among U.S. States, July 2010

3122 Douglas Gollin and Christian Zimmermann, Global Climate Change and the Resurgence of Tropical Disease: An Economic Approach, July 2010

3123 Francesco Daveri and Maria Laura Parisi, Experience, Innovation and Productivity Empirical Evidence from Italy's Slowdown, July 2010

3124 Carlo V. Fiorio and Massimo Florio, A Fair Price for Energy? Ownership versus Market Opening in the EU15, July 2010

3125 Frederick van der Ploeg, Natural Resources: Curse or Blessing?, July 2010

3126 Kaisa Kotakorpi and Panu Poutvaara, Pay for Politicians and Candidate Selection: An Empirical Analysis, July 2010

3127 Jun-ichi Itaya, Makoto Okamura and Chikara Yamaguchi, Partial Tax Coordination in a Repeated Game Setting, July 2010

3128 Volker Meier and Helmut Rainer, On the Optimality of Joint Taxation for NonCooperative Couples, July 2010

3129 Ryan Oprea, Keith Henwood and Daniel Friedman, Separating the Hawks from the Doves: Evidence from Continuous Time Laboratory Games, July 2010

3130 Mari Rege and Ingeborg F. Solli, The Impact of Paternity Leave on Long-term Father Involvement, July 2010

3131 Olaf Posch, Risk Premia in General Equilibrium, July 2010

3132 John Komlos and Marek Brabec, The Trend of BMI Values by Centiles of US Adults, Birth Cohorts 1882-1986, July 2010

3133 Emin Karagözoğlu and Arno Riedl, Information, Uncertainty, and Subjective Entitlements in Bargaining, July 2010

3134 John Boyd, Gianni De Nicolò and Elena Loukoianova, Banking Crises and Crisis Dating: Theory and Evidence, July 2010

3135 Michael R. Baye, Dan Kovenock and Casper G. de Vries, The Herodotus Paradox, July 2010

3136 Martin Kolmar and Hendrik Rommeswinkel, Group Contests with Complementarities in Efforts, July 2010 